\title{
Atrial pacing as an adjunct to the management of post-surgical His bundle tachycardia
}

\author{
Jan A Till, Edward Rowland
}

\begin{abstract}
Objective-To examine the benefits of restoring atrioventricular synchrony to children with His bundle tachycardia after operation for congenital heart disease.
\end{abstract}

Design-Review of clinical outcome of adopting the technique of $R$ wave synchronised atrial pacing as an adjunct to the management of His bundle tachycardia from September of 1987 till June of 1990.

Patients-Eleven consecutive children (aged between 3 days and 13 years) with haemodynamically significant $\mathrm{His}$ bundle tachycardia after cardiopulmonary bypass surgery.

Interventions-Atrial pacing synchronised either manually or automatically to the $R$ wave of the His bundle tachycardia was implemented so that atrial depolarisation preceded the following $R$ wave by an appropriate $P R$ interval.

Results-An immediate and sustained increase in mean systemic blood pressure (average $15 \mathrm{~mm} \mathrm{Hg}$, range 6-30 $\mathrm{mm} \mathrm{Hg}$ ) was seen with the onset of atrial pacing in 10 of the 11 children. One child, who had undergone a Fontan procedure, developed atrial flutter shortly after the onset of atrial pacing and required direct current cardioversion. Four children died. Of the seven survivors, six have sustained sinus rhythm which returned between two and 10 days after the onset of tachycardia. One of the survivors has severe neurological impairment attributed to a period of low cardiac output during tachycardia; the others are alive and well. In those children who did badly the mean time between arrhythmia occurrence and the start of atrial pacing or cooling or both was nine hours; in those who did well it was one hour.

Conclusions-Atrial pacing synchronous with the His bundle is a useful adjunct in the management of children with His bundle tachycardia after surgery for congenital cardiac disease.

His bundle tachycardia occurring soon after operation for congenital heart disease is associated with a high mortality and significant morbidity. ${ }^{12}$ Rapid tachycardia rates combine with loss of atrioventricular synchrony to limit severely cardiac output. Management is difficult because the arrhythmia is unresponsive to conventional methods of treatment. Should the child survive, the natural history is one of spontaneous termination between three to eight days after surgery. Though antiarrhythmic drugs may be helpful their use is limited by the severe haemodynamic impairment that frequently accompanies this arrhythmia. Bash et al successfully controlled the tachycardia rate in three children with corporal cooling and these and other workers have used atrial pacing at a rate greater than that of the tachycardia to further increase cardiac output after the rate has been reduced. ${ }^{3}$ We used a new technique to restore atrioventricular synchrony. We synchronised the atrial pacing to the $R$ wave of the tachycardia so that atrioventricular synchrony was restored without a further increase in heart rate and we evaluated the success of this approach as an adjunct to other methods of controlling post-surgical His bundle tachycardia.

\section{Patients and methods}

Between September 1987 and June 1990 we treated 11 consecutive children for haemodynamically significant post-surgical His bundle tachycardia. Their ages ranged between three days and 13 years. All developed His bundle tachycardia in the immediate postoperative period after operation for various congenital anomalies (table 1). Four children underwent complete correction of tetralogy of Fallot, two correction of double outlet right ventricle with subaortic ventricular septal defect, one patch closure of ventricular septal defect, one complete repair of atrioventricular septal defect, one complete repair of common arterial trunk with a homograft, one a mitral valvuloplasty for a dysplastic mitral valve, and one a Fontan procedure for tricuspid atresia. All operations were performed on cardiopulmonary bypass and were considered a "successful" repair by the surgeon at the time of operation. Two children (patients 1 and 5) developed complete atrioventricular block during surgery. Complete atrioventricular block was diagnosed by the presence of atrioventricular dissociation with a ventricular rate slower than and independent of that of the atria. His bundle tachycardia was diagnosed within six hours of surgery in seven of the children, within 12 hours in a further three, and in one child His bundle tachycardia developed 30 hours after operation. The two children who 
Table 1 Patient details at onset of His bundle tachycardia

\begin{tabular}{rllllll}
\hline $\begin{array}{l}\text { Case } \\
\text { No }\end{array}$ & Age & Diagnosis & Surgery & $\begin{array}{l}\text { HBT rate } \\
\text { (beats/min) }\end{array}$ & Inotropic support & $\begin{array}{c}\text { VA } \\
\text { conduction }\end{array}$ \\
\hline 1 & 3 days & Dysplastic mitral valve & Repair & 210 & Dopamine, adrenaline & - \\
2 & $7 \mathrm{wk}$ & VSD & Patch & 205 & Dopamine, isoprenaline & + \\
3 & $6 \mathrm{mnth}$ & DORV & C & 240 & Dopamine, adrenaline, dobutamine & - \\
4 & $8 \mathrm{mnth}$ & TOF & $\mathrm{C}$ & 230 & Dopamine, adrenaline & - \\
5 & $9 \mathrm{mnth}$ & TOF & $\mathrm{C}$ & 200 & Dopamine, adrenaline & - \\
6 & $11 \mathrm{mnth}$ & TOF/AVSD & C & 210 & Dopamine, adrenaline & + \\
7 & $1 \mathrm{yr}$ & AVSD & C & 190 & Dopamine & - \\
8 & $11 \mathrm{yr}$ & TOF/VPS & Fopamine & - \\
9 & $13 \mathrm{yr}$ & TA & C & 215 & Dopamine, isoprenaline & Dopamine, isoprenaline, dobutamine, \\
10 & $15 \mathrm{mnth}$ & DORV & adrenaline & - \\
11 & $10 \mathrm{mnth}$ & Truncus & C & 230 & Dopamine, dobutamine, adrenaline & -
\end{tabular}

AVSD, atrioventricular septal defect; C, complete correction; DORV, double outlet right ventricle with subaortic ventricular septal defect; HBT, His bundle tachycardia; VSD, ventricular septal defect; TOF, tetralogy of Fallot; TA, tricuspid atresia; Truncus, common arterial trunk; VPS, valvar pulmonary stenosis.

had previously had complete atrioventricular block developed His bundle tachycardia at 12 and 30 hours. Diagnosis of His bundle tachycardia was made from the surface electrocardiogram in most children and confirmed when necessary by recordings from atrial or ventricular electrodes (fig 1). The criteria for diagnosis were $(a)$ heart rate greater than the 98th percentile for age, $(b)$ a QRS configuration in tachycardia similar to that in sinus rhythm or to that with atrial pacing, and (c) the presence of atrioventricular dissociation with a ventricular rate greater than the atrial rate or retrograde ventriculo-atrial conduction. The maximum rate of tachycardia ranged from 170 beats/minute to 280 beats/minute (mean 216 ). All patients developed a severe low cardiac output with the onset of tachycardia and seven were oliguric with a urine output less than $1 \mathrm{ml} / \mathrm{kg} /$ hour. Initial management varied because it was undertaken by the doctor in charge of intensive care. All were treated with inotropic drugs to support a falling blood pressure. These included dopamine, dobutamine, adrenaline, and isoprenaline. A mean of $2 \cdot 2$ inotropic drugs were being given when $\mathrm{His}$ bundle tachycardia was recognised. All patients were receiving routine antibiotic treatment of flucloxacillin and gentamicin.

Eight children were initially treated with antiarrhythmic drugs. Amiodarone was used in six ( $5 \mathrm{mg} / \mathrm{kg}$ intravenously over 20 minutes) followed by a continuous infusion $(15 \mathrm{mg} / \mathrm{kg} /$ day) and resulted in a reduction of tachycardia rate in five but failed to restore sinus rhythm in any child. One child who became hypotensive 10 minutes after the administration of amio-

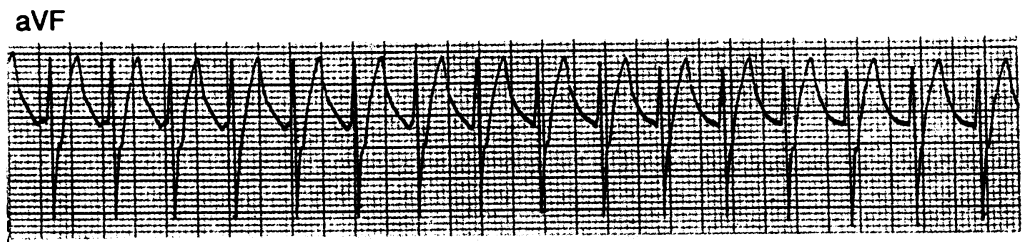

Recording from atrial epicardial electrode

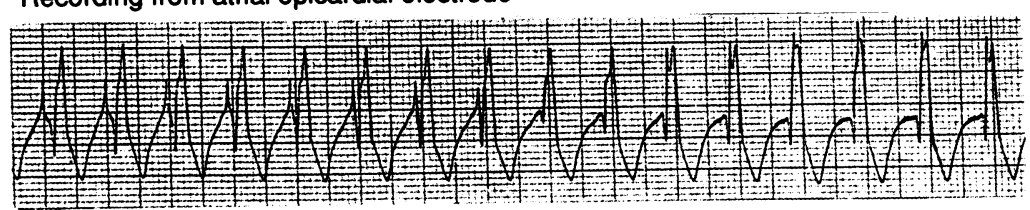

Figure 1 Surface electrocardiogram (lead aVF) and simultaneous recording from a temporary atrial electrode showing atrioventricular dissociation (after cooling). darone was given an intravenous bolus of calcium which precipitated ventricular fibrillation. One child was given flecainide $(2 \mathrm{mg} / \mathrm{kg}$ intravenously over 10 minutes) and again this reduced the tachycardia rate but without return to sinus rhythm. An intravenous infusion of flecainide was therefore continued for a further 36 hours. Digoxin (standard intravenous loading dose for age followed by a maintenance regimen) was given to three without an immediately recognisable beneficial effect. One child was cardioverted with direct current without effect and in three further children atrial overdrive pacing, used in an attempt to terminate the arrhythmia and regain sinus rhythm, was unsuccessful. Ten children were surface cooled to a core temperature of $32^{\circ} \mathrm{C}$ with cooling blankets and ice packs. In all patients we used vecuronium to achieve paralysis and chloral hydrate or midazolam for sedation.

Atrial pacing was used to restore atrioventricular synchrony in all 11 children. The atrial pacing stimulus was synchronised with the $R$ wave of the tachycardia either manually or automatically so that atrial depolarisation preceded ventricular depolarisation by a physiological atrioventricular interval. Initially we manually adjusted the relation of the atrial pacing stimulus to the $R$ wave of the successive QRS complex by means of a simple standard temporary pacing box and two atrial wires. Having recognised the success of the technique we produced the same effect automatically by using two stimulators in concert-one to receive the input from the ventricle and the other to pace the atrium after a preset delay. We achieved a similar result with a dual chamber analyser (Medtronic) when the ventricular temporary pacing wires were connected to the atrial input and the atrial wires were attached to the ventricular output in the VDD pacing mode with an atrioventricular delay set so that the atrial pacing stimulus preceded the subsequent QRS complex by an appropriate interval. In six children we used temporary epicardial pacing wires placed at operation. However, five children did not have epicardial atrial pacing wires on their return from the operating theatre. In three of these five we used an oesophageal electrode until pacing was shown to be effective, then the chest was reopened in two to place temporary epicardial wires and a temporary transvenous electrode 
A

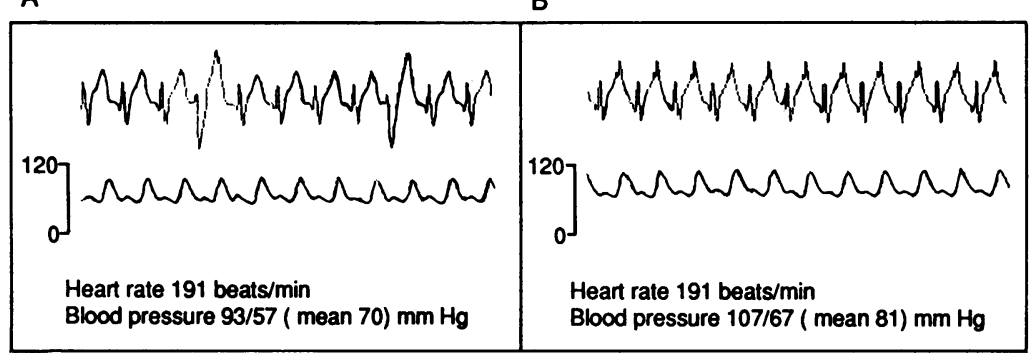

Figure 2 (A) Electrocardiogram and systemic blood pressure trace in patient 8 before onset of $R$ wave synchronised atrial pacing. (B) Electrocardiogram and systemic blood pressure trace in the same patient after onset of $R$ wave synchronised atrial pacing.

was positioned in the third. A further two children had their chest opened as an emergency procedure to relieve "atypical tamponade" and at that stage temporary epicardial atrial wires were placed. ${ }^{4}$

\section{Results}

Cooling was attempted in 10 children and was successful in eight. In one obese child (patient $9,68 \mathrm{~kg}$ ) attempts at cooling were abandoned after 10 hours when a core temperature of less than $35^{\circ} \mathrm{C}$ had still not been reached. An infant died before cooling was achieved. In the eight patients in whom cooling was successful a core temperature of $33^{\circ} \mathrm{C}$ or less was achieved between 30 minutes and four hours from onset. A reduction in tachycardia rate was achieved in all eight children. During this time three children became persistently mildly acidotic and two became hypoglycaemic but no other side effects were seen. It was not clear whether the metabolic disturbance resulted directly from a low cardiac output state or arose as a consequence of cooling. Cooling was maintained for up to seven days (mean 3.8 days). Coincident with cooling atrial pacing was used to restore atrioventricular synchrony. Cardiac output was not measured directly but mean blood pressure increased immediately with onset of atrial pacing (average increase in mean blood pressure $15 \mathrm{~mm} \mathrm{Hg}$, range $6-30 \mathrm{~mm} \mathrm{Hg}$ ) in 10 of the 11 children and was sustained (fig 2). Urine output, assessed over the three hour period before pacing and the three hour period after the onset of pacing, increased in six. In two children the urine output had already fallen to zero and there was no increase in urine output despite an apparent improvement in haemodynamic state; in three others the urine output remained low (table 2). The haemodynamic improvement allowed a slow withdrawal of inotropic drugs in nine children over the ensuing 24 hours. In one child atrial flutter developed within the first hour of starting atrial pacing (fig 3). This was the child who had undergone a Fontan procedure for tricuspid atresia (patient 9). At the time of pacing this child had a central venous pressure of 18 $\mathrm{mm} \mathrm{Hg}$. The atrial flutter rate was 300 beats/ minute, a rate greater than that of the His bundle tachycardia, and it was conducted to the ventricle at a rate of 300 beats/minute. This new arrhythmia resulted in further haemodynamic compromise and it was treated immediately with direct current cardioversion. Atrial flutter was terminated; His bundle tachycardia resumed and despite the resumption of atrial pacing atrial flutter was not seen again.

The underlying rate and rhythm were assessed regularly. Atrial pacing was stopped at least daily to estabiish whether the child could manage without pacing. Similarly, after haemodynamic stability had been achieved the child was rewarmed at intervals to see whether he would tolerate a higher temperature. Seven children survived. Of these, six returned to sinus rhythm after 2-10 days (mean 6 days) and one returned to a slow junctional rhythm. One survivor suffered extensive neurological damage attributed to low cardiac output. Four of the 11 children died. One died shortly after the tachycardia was recognised and neither cooling nor atrial pacing had been well established. We think that this child had had unrecognised episodes of His bundle tachycardia four hours after the operation. Atrial pacing and cooling were delayed until 20 hours. Three further children died despite effective atrial pacing and cooling. Though the small numbers do not allow proper statistical analysis an important factor contributing to outcome in some children seemed to be the length of time the child was in His bundle tachycardia before atrial pacing or cooling or both were started. In children who are alive and well (patients 2, 3, 5, 7,10 , and 11) the mean time between the occurrence of arrhythmia and the start of pacing and cooling was approximately one hour. In contrast, in the group who did badly (patients 1, 4, 6, 8, and 9) the mean time between arrhythmia occurrence and the start of pacing and cooling was nearly nine hours.

Table 2 Treatment details

\begin{tabular}{|c|c|c|c|c|c|c|}
\hline $\begin{array}{l}\text { Case } \\
\text { No }\end{array}$ & $\begin{array}{l}\text { Time of occurrence } \\
\text { after surgery }(h)\end{array}$ & $\begin{array}{l}\text { Time of recognition } \\
\text { after surgery }(h)\end{array}$ & $\begin{array}{l}\text { Time of } \\
\text { pacing }(h)\end{array}$ & $\begin{array}{l}\star \text { Urine output } \\
\text { before pacing } \\
(\mathrm{ml} / \mathrm{kg} / \mathrm{h})\end{array}$ & $\begin{array}{l}\star \text { Urine output } \\
\text { after pacing } \\
(\mathrm{ml} / \mathrm{kg} / \mathrm{h})\end{array}$ & $\begin{array}{l}\text { Antiarrhythmic } \\
\text { drugs }\end{array}$ \\
\hline $\begin{array}{r}1 \\
2 \\
3 \\
4 \\
5 \\
6 \\
7 \\
8 \\
9 \\
10 \\
11\end{array}$ & $\begin{array}{r}12 \\
3 \\
0 \\
4 \\
30 \\
2 \\
10 \\
0 \\
4 \\
3 \\
4 \cdot 5\end{array}$ & $\begin{array}{r}18 \\
3 \\
0 \\
20 \\
30 \\
4 \\
12 \\
22 \\
4 \\
3 \\
4 \cdot 8\end{array}$ & $\begin{array}{l}18 \\
3 \\
2 \cdot 5 \\
20 \\
30 \\
2 \\
14 \\
22 \\
4 \\
5 \\
5 \cdot 5\end{array}$ & $\begin{array}{c}0.5 \\
.1 \\
1.4 \\
<1 \\
0.4 \\
0 \\
<1 \\
1 \\
>1 \\
<1 \\
0.6\end{array}$ & $\begin{array}{l}2 \\
1 \cdot 8 \\
4 \\
0 \\
2 \cdot 4 \\
0 \\
<1 \\
<1 \\
<1 \\
>1 \\
1 \cdot 3\end{array}$ & $\begin{array}{l}\overline{-} \\
\text { Amiodarone } \\
\text { Amiodarone } \\
\text { Digoxin, amiodarone } \\
\overline{\text { Flecainide }} \\
\text { Digoxin, amiodarone } \\
\text { Amiodarone } \\
\text { Digoxin, adenosine } \\
\text { Amiodarone, adenosine }\end{array}$ \\
\hline
\end{tabular}

$\star$ Urine output was assessed over a three hour period before and after the start of atrial pacing. 

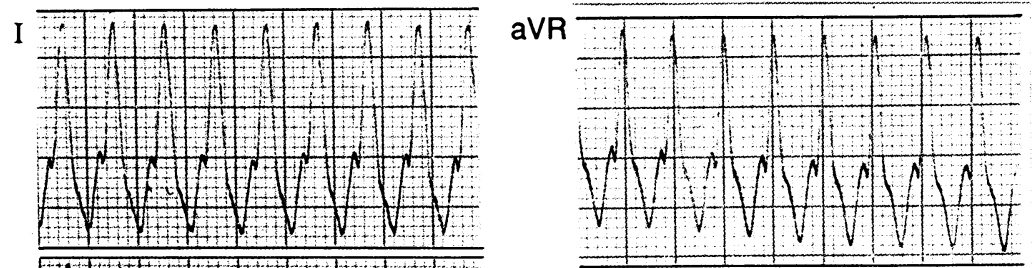

II $A+A+A+A D A+A D A+A$

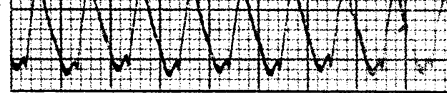

III)

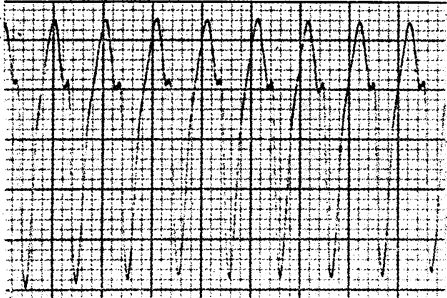

aVL

aVF

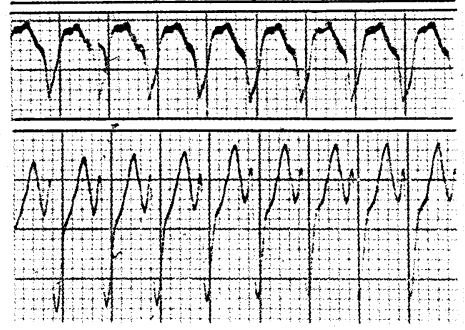

Figure 3 Electrocardiogram (limb leads) in patient 9 showing atrial flutter. (300 beats/min). recovery of complete atrioventricular block; intact atrioventricular conduction during $\mathrm{His}$ bundle tachycardia was demonstrable with atrial pacing in both children. One child later died but the other recovered sinus rhythm without further evidence of complete atrioventricular block.

His bundle tachycardia, whether occurring in the immediate postoperative period or as a congenital arrhythmia in an otherwise structurally "normal" heart, is largely refractory to conventional antiarrhythmic drugs. Grant et al described a beneficial response (a small decrease in rate) to digoxin in six of a group of eight patients after operation. However, this favourable response was not seen by others. Garson et al did not see any beneficial response in seven similar children 90 minutes after loading with digoxin; and Sholler et al noted little response in nine of 18 children, a small decrease in rate in six, and an increase in tachycardia rate in three patients treated with digoxin alone. ${ }^{910}$ In both types of $\mathrm{His}$ bundle tachycardia the success of propranolol and verapamil has been limited; indeed an increase in tachycardia rate with consequent haemodynamic collapse has been described after administation of verapamil in the congenital form of the arrhythmia. ${ }^{911} 12$ These workers suggested that the increase in arrhythmia rate seen after intravenous verapamil may represent a reflex response to vasodilatation.

More recently some success has been claimed with the newer class 1c drugs, propafenone and flecainide. There are good theoretical reasons why these agents should suppress this tachycardia because they are potent depressants of automaticity in vitro. Administration of these drugs to critically ill children may be difficult, however, because of their known negative inotropic properties. Garson et al used propafenone to treat seven children with postoperative $\mathrm{His}$ bundle tachycardia. The His bundle tachycardia rate was significantly reduced but Garson et al recommended slow administration because they saw a significant fall in blood pressure that required a plasma infusion to restore blood pressure to an acceptable level. ${ }^{9}$ Wren and Campbell reported a patient in whom congenital His bundle tachycardia responded to flecainide. ${ }^{13}$ Amiodarone has also been used in the management of both congenital and postoperative His bundle tachycardia. Villain et al report the successful reduction of rate to below 150 beats/minute in eight of 14 children with

Table 3 Outcome

\begin{tabular}{|c|c|c|c|c|c|c|c|}
\hline \multirow{2}{*}{$\frac{\text { Case No }}{1}$} & \multicolumn{2}{|c|}{ Cooling time (days) } & \multicolumn{2}{|c|}{ Pacing time (days) } & \multirow{2}{*}{$\begin{array}{l}\text { Outcome } \\
\text { Died }\end{array}$} & \multirow{2}{*}{ Resolution of $H B T$ (days) } & \multirow{2}{*}{ Rhythm } \\
\hline & Yes & 3 & Yes & 3 & & & \\
\hline 2 & Yes & 5 & Yes & 6 & Alive/well & 5 & SR \\
\hline 3 & Yes & 5 & Yes & 5 & Alive/well & 6 & SR \\
\hline 4 & NA & - & NA & - & Died & - & - \\
\hline 5 & Yes & 7 & Yes & 7 & Alive/well & 6 & SR \\
\hline 6 & Yes & 1 & Yes & 1.5 & Died & - & - \\
\hline 7 & No & - & Yes & 1.5 & Alive/well & 10 & SR \\
\hline 8 & Yes & 1 & Yes & 1 & Died & - & - \\
\hline 9 & $\mathrm{NA}$ & - & Yes & 2 & Alive/NI & 2 & JR \\
\hline 10 & Yes & 5 & Yes & 5 & Alive/well & 7 & SR \\
\hline 11 & Yes & 4 & Yes & 4 & Alive & 4 & SR \\
\hline
\end{tabular}

JR, junctional escape rhythm; NA, not achieved; NI, neurological impairment; SR, sinus rhythm. 
congenital arrhythmia. ${ }^{14}$ When we used amiodarone in post-surgical patients we reported a reduction in tachycardia rate in four of seven patients though in no case did amiodarone terminate tachycardia and restore sinus rhythm. ${ }^{2}$

Bash et al recently reported a novel approach to management-the use of corporal cooling in three young children who developed His bundle tachycardia postoperatively. ${ }^{3}$ Hypothermia has long been recognised as a means of suppressing the automaticity of cells but has only recently been applied clinically. In our small series cooling seemed to be successful in bringing about a controlled decrease in tachycardia rate and was accompanied by few side effects. A criticism of our study is that we used several treatments at the same time. We believed that it was unethical to stop a treatment that might prove beneficial in such a life-threatening condition in order to evaluate properly another new treatment. Therefore the three children in whom digoxin had been started continued to receive digoxin throughout the evaluation period. Similarly, amiodarone was continued in four children and flecainide in one. The decisions to cool and pace the child were often made at the same time but cooling took longer to achieve. The effects of atrial pacing were therefore assessed at normothermia in some children. Even without cooling there was an increase in mean blood pressure with a steady decline in heart rate which we attributed to an improvement in haemodynamic state caused by pacing. Also in some cases cooling was achieved first because $R$ wave synchronised atrial pacing required a physician familiar with pacing to be on site. In these patients cooling was associated with a stabilisation in haemodynamic state and a steady decline in heart rate in most patients. An additional beneficial effect was seen when pacing started.

Waldo and colleagues described a different approach to the problem of $\mathrm{His}$ bundle tachycardia. ${ }^{8}$ They reported a case of postsurgical His bundle tachycardia in which the mechanical ventricular rate was halved by paired ventricular pacing. The highly refractory nature of His bundle tachycardia has led some clinicians to ablate permanently the His bundle in children with the congenital form. ${ }^{15} 16$ This more radical and permanent approach results in complete atrioventricular block and necessitates implantation of a permanent pacemaker. None of the treatments previously described, however, has returned the child to sinus rhythm and therefore even if the rate is reduced there remains atrioventricular dissociation or, at worst, ventriculoatrial conduction resulting in atrial contraction almost coincident with ventricular contraction. Though cardiac output in small children is predominantly rate dependent, cardiac output can be significantly increased in the sick heart by the addition of atrial contraction at the correct time in the cardiac cycle. We restored atrioventricular synchrony to these patients without a further increase in heart rate, and in our group the restoration of atrioventricular synchrony was associated with an immediate and beneficial response in 10 of the 11 children. His bundle tachycardia is unlike the more common arrhythmias seen in childhood in that the rate is variable because it is highly dependent upon autonomic tone. In these children it is important to minimise any further reflex increase in tachycardia rate by preventing falls in blood pressure and by limiting the use of sympathomimetic drugs. Our results confirm that early recognition followed by vigorous appropriate management are key features in avoiding this vicious cycle of deterioration in these patients. They also emphasise the need for the routine placement of temporary pacing wires after surgery for congenital heart disease even if complete atrioventricular block is not present. A treatment that can take effect immediately, is without adverse actions, and can produce a beneficial response in cardiac output has considerable advantages.

1 Krongrad E. Postoperative arrhythmias in patients with congenital heart disease. Chest 1984;85:107-13.

2 Till JA, Rowland E, Rigby $M$. His bundle tachycardia: an important cause of postoperative mortality and morbidity. In: Crupi G, Parenzan L, Anderson RH, eds. Perspectives in paediatric cardiology. New York: Futura Publishing Company, 1990;2(3):269-72.

3 Bash S, Shah JJ, Albers WH, Geiss DM. Hypothermia for the treatment of postsurgical greatly accelerated junctional ectopic tachycardia. J Am Coll Cardiol 1987;10: 1095-9.

4 Shore DF, Capuani A, Lincoln C. Atypical tamponade after cardiac operation in infants and children. $J$ Thorac Cardiovasc Surg 1982;83:449-52.

5 Grant JW, Serwer GA, Armstrong BE, Oldham HN, Anderson PAW. Junctional tachycardia in infants and Anderson PAW. Junctional tachycardia in infants and children after open heart surgery for

6 Rosen MR, Fisch C, Hoffman BF, Danilo P, Lovelace DE Knoebel SB. Can accelerated atrioventricular junctional escape rhythms be explained by delayed afterdepolarizaescape rhythms be explained by delayed

7 Garson A, Gillette PC. Junctional ectopic tachycardia in children: electrocardiology, electrophysiology and phar macological response. Am J Cardiol 1979;44:298-302.

8 Waldo AL, Krongrad E, Kupersmith J, Levine R, Bowman FO, Hoffman BF. Ventricular paired pacing to control rapid ventricular heart rate following open heart surgery. Circulation 1976;53:176-81.

9 Garson A, Moak JP, Smith RT, Norton JB. Usefulness of intravenous propafenone for control of postoperative junctional ectopic tachycardia. Am J Cardiol 1987; $59: 1422-4$

10 Sholler GF, Walsh EP, Mayer JE, Saul JP, Gamble WJ, Lang P. Evaluation of staged treatment protocol for postoperative rapid junctional tachycardia [abstract]. Circulation 1988;78(suppl 11):597.

11 Bucknall C, Ladusans E, Tynan MJ, Curry PVL. Ventricular tachycardia masquerading as supraventricular tricular tach [abstract]. Am Heart J 1967;73:814.

12 Karpawich PP. Junctional ectopic tachycardia in an infant: electrophysiologic evaluation. Am Heart $J$ 1985;109: 159-60.

13 Wren C, Campbell RWF. His bundle tachycardia-arrhythmogenic and antiarrhythmic effects of therapy. Eur Heart $J$ 1987;8:647-50.

14 Villain E, Vetter VL, Garcia JM, Herre J, Cifarelli A, Garson A. Evolving concepts in the management of congenital junctional ectopic tachycardia. Circulation 1990;81:1544-9.

15 Gillette PC, Garson A, Coburn JP, et al. Junctional automatic ectopic tachycardia: new proposed treatment by transcatheter His bundle ablation. Am Heart J 1983; 106:619-23.

16 Gillette PC. Diagnosis and management of postoperative junctional ectopic tachycardia. Am Heart J 1989;118: 192-4. 